\title{
Immunostimulatory property of a synthetic peptide belonging to the soluble ATP diphosphohydrolase isoform (SmATPDase 2) and immunolocalisation of this protein in the Schistosoma mansoni egg
}

\author{
Rita Gabriela Pedrosa Ribeiro Mendes' ${ }^{1}$, Michélia Antônia do Nascimento Gusmão', \\ Ana Carolina Ribeiro Gomes Maia' ${ }^{1}$, Michelle de Lima Detoni', Gabriane Nascimento Porcino', \\ Thais Vieira Soares ${ }^{1}$, Maria Aparecida Juliano², Luiz Juliano², Paulo Marcos Zech Coelho ${ }^{3}$, \\ Henrique Leonel Lenzi ${ }^{4+}$, Priscila Faria-Pinto ${ }^{1}$, Eveline Gomes Vasconcelos ${ }^{1 /+}$
}

\footnotetext{
1Departamento de Bioquímica, Instituto de Ciências Biológicas, Universidade Federal de Juiz de Fora, Juiz de Fora, MG, Brasil ${ }^{2}$ Departamento de Biofísica, Escola Paulista de Medicina, Universidade Federal de São Paulo, São Paulo, SP, Brasil ${ }^{3}$ Instituto de Pesquisas René Rachou-Fiocruz, Belo Horizonte, MG, Brasil ${ }^{4}$ Laboratório de Patologia, Instituto Oswaldo Cruz-Fiocruz, Rio de Janeiro, RJ, Brasil
}

A peptide (SmB2LJ; r175-194) that belongs to a conserved domain from Schistosoma mansoni SmATPDase 2 and is shared with potato apyrase, as predicted by in silico analysis as antigenic, was synthesised and its immunostimulatory property was analysed. When inoculated in BALB/c mice, this peptide induced high levels of SmB2LJ-specific IgG1 and IgG2a subtypes, as detected by enzyme linked immunosorbent assay. In addition, dot blots were found to be positive for immune sera against potato apyrase and SmB2LJ. These results suggest that the conserved domain r175-194 from the $\mathrm{S}$. mansoni SmATPDase 2 is antigenic. Western blots were performed and the anti-SmB2LJ antibody recognised in adult worm (soluble worm antigen preparation) or soluble egg antigen antigenic preparations two bands of approximately 63 and $55 \mathrm{kDa}$, molecular masses similar to those predicted for adult worm SmATPDase 2. This finding strongly suggests the expression of this same isoform in S. mansoni eggs. To assess localisation of SmATPDase 2, confocal fluorescence microscopy was performed using cryostat sections of infected mouse liver and polyclonal antiserum against SmB2LJ. Positive reactions were identified on the external surface from the miracidium in von Lichtenberg's envelope and, in the outer side of the egg-shell, showing that this soluble isoform is secreted from the $\mathrm{S}$. mansoni eggs.

Key words: Schistosoma mansoni - NTPDase - potato apyrase - peptide

ATP diphosphohydrolases (EC 3.6.1.5), also known as apyrases or NTPDases, hydrolyse nucleosides di and triphosphate to the corresponding nucleoside monophosphates upon bivalent metal ion activation. They belong to the ATP diphosphohydrolase family, which shares five apyrase-conserved regions that are involved in the catalytic cycle (Robson et al. 2006, Sansom et al. 2008, Vasconcelos et al. 2009).

Two Schistosoma mansoni ATP diphosphohydrolase isoforms of approximately $63 \mathrm{kDa}$, which differ in their catalytic properties, solubilities and sensitivities to nonionic detergents, were partially purified from both adult worm tegument and homogenised egg preparations (Vasconcelos et al. 1993, 1996, Faria-Pinto et al. 2004). The cloning of two $S$. mansoni ATP diphosphohydrolase genes (SmATPDases 1 and 2) from the adult worm was

Financial support: FAPEMIG (CBB-APQ-01384-09, CBB-APQ 00754-09), CNPq, UFJF, CAPES (to RGPRM, MANG, TVS, ACRGM, MLD, GNP)

RGPRM, MLD and GNP were recipients of Master Degree fellowships from the UFJF/MG and CAPES/REUNI.

† In memoriam

+ Corresponding author: evascon@powerline.com.br

Received 17 December 2010

Accepted 6 May 2011 reported and these genes were shown to encode proteins that belong to the ATP diphosphohydrolase family (DeMarco et al. 2003, Levano-Garcia et al. 2007).

In silico analysis showed that $S$. mansoni SmATPDase 1 protein, of predicted molecular weight 61,353 Da, has two transmembrane domains and a high structural similarity to identified mammalian membrane-associated NTPDases (DeMarco et al. 2003). The amino acid sequence of the SmATPDase 2 protein, of predicted molecular weight $63,785 \mathrm{Da}$, is more closely related to mammalian NTPDases 5 and 6 (Levano-Garcia et al. 2007). The functions of these proteins have been associated with protective mechanisms against the host organism under conditions that involve ATP or ADP effects, such as immune responses and platelet activation, and they are possible targets for the treatment of schistosomiasis (Vasconcelos et al. 1993, 1996, Faria-Pinto et al. 2004, Penido et al. 2007, Oliveira et al. 2008).

The two native S. mansoni ATP diphosphohydrolase isoforms (SmATPDases 1 and 2 proteins) have cross-immunoreactivity with polyclonal anti-potato apyrase antibodies, suggesting that they share epitopes (Vasconcelos et al. 1996, Faria-Pinto et al. 2004). In addition, total IgG antibody from the serum of $S$. mansoni-infected mice or schistosomiasis patients recognised potato apyrase. This finding was in accordance with the existence of antigenic domains within these parasite ATP diphosphohy- 
drolase isoforms, as these epitopes are shared with those from vegetable proteins (Faria-Pinto et al. 2004, 2008, $2010 \mathrm{a}, \mathrm{b})$. Domains of high identity between potato apyrase and the $S$. mansoni SmATPDase 2 were observed by alignment of their primary amino acid sequences and by hypothetical three-dimensional models, suggesting that these conserved domains may be exposed and available for antibody binding (Faria-Pinto et al. 2008, Vasconcelos et al. 2009).

Identification and characterisation of epitopes within an antigenic protein may help select components for the development of a defined vaccine against schistosomiasis or for diagnostic purposes (Kusel et al. 2007, Oliveira et al. 2008). In this study, a peptide (SmB2LJ) that belongs to a conserved domain from S. mansoni SmATPDase 2, shared with potato apyrase, was synthesised and its immunostimulatory capability was analysed. In addition, mouse polyclonal anti-SmB2LJ antibodies were used in Western blotting and immunocytochemistry techniques to identify a SmATPDase 2-like protein in a soluble egg antigen (SEA) preparation and $S$. mansoni eggs.

\section{MATERIALS AND METHODS}

Animals - Eight-week-old male Swiss mice were subcutaneously infected with approximately 100 cercariae of S. mansoni obtained from infected Biomphalaria glabrata snails, as described by Smithers and Terry (1965). After seven weeks, these mice were used to obtain worms, eggs and specimens of liver. These studies were approved by the Ethical Committee of the Federal University of de Juiz de Fora, Juiz de Fora, state of Minas Gerais, Brazil (protocol 017/2009).

Potato apyrase, synthetic peptide, SEA and soluble worm antigen preparation (SWAP) - Potato apyrase was purified from a commercial strain of Solanum tuberosum and used to obtain polyclonal antiserum in a New Zealand White rabbit or BALB/c mice, as earlier described (FariaPinto et al. 2004, 2006, 2010b, Kettlun et al. 2005). A peptide (SmB2LJ; r175-194; AALSLTKLINIAETSLPVDV) belonging to a conserved domain from soluble S. mansoni SmATPDase 2 (GenBank accession ABI79456.1) was designed based on a strategic comparative study with its potato apyrase counterpart (r97-116; AANSLEPLLDGAEGVVPQEL; $40 \%$ identity and $65 \%$ similarity over 20 amino acids) (GenBank accession P80595), which maintained the predicted epitopes available for antibody binding (Faria-Pinto et al. 2008). The amino acid sequence of SmB2LJ peptide has lower identity (20-30\%) and similarity (40-55\%) with its $S$. mansoni SmATPDase 1 (accession AAP94734) counterpart or with amino acid sequence of either S. mansoni GDPase (CAZ35542.1), mouse NTPDase 5 (NP_001021385.1) or mouse NTPDase 6 (NP_742115.2) counterpart. The synthetic peptide was obtained by solid-phase synthesis and purified as previously described (Korkmaz et al. 2008). The molecular mass and purity of the synthesised peptide were confirmed by amino acid analysis and by MALDI-TOF using a Microflex-LT mass spectrometer (Bruker-Daltonics, Billerica, MA, USA). SEA and SWAP preparations were obtained as previously described (Colley et al. 1977).
Development of polyclonal antiserum against Sm$B 2 L J$ - Polyclonal antiserum against SmB2LJ was obtained from seven-week old BALB/c mice $(n=4)$ that were inoculated by a peritoneal route with two injections of SmB2LJ $(10 \mu \mathrm{g})$. The first injection was emulsified in Freund's complete adjuvant and the second injection was in Freund's incomplete adjuvant and delivered in 15-day intervals. Pre-immune sera were obtained before inoculation of the SmB2LJ. In addition, serum samples obtained from BALB/c mice $(n=4)$ that were inoculated under the same experimental conditions with both complete and incomplete Freund adjuvant in the absence of the peptide were used for specificity controls. The sera were stored at $-20^{\circ} \mathrm{C}$.

Dot blots of SmB2LJ and potato apyrase - For dot blot analysis, purified potato apyrase $(1 \mu \mathrm{g})$ or peptide $\mathrm{Sm}$ B2LJ $(5 \mu \mathrm{g})$ was spotted onto nitrocellulose membranes,
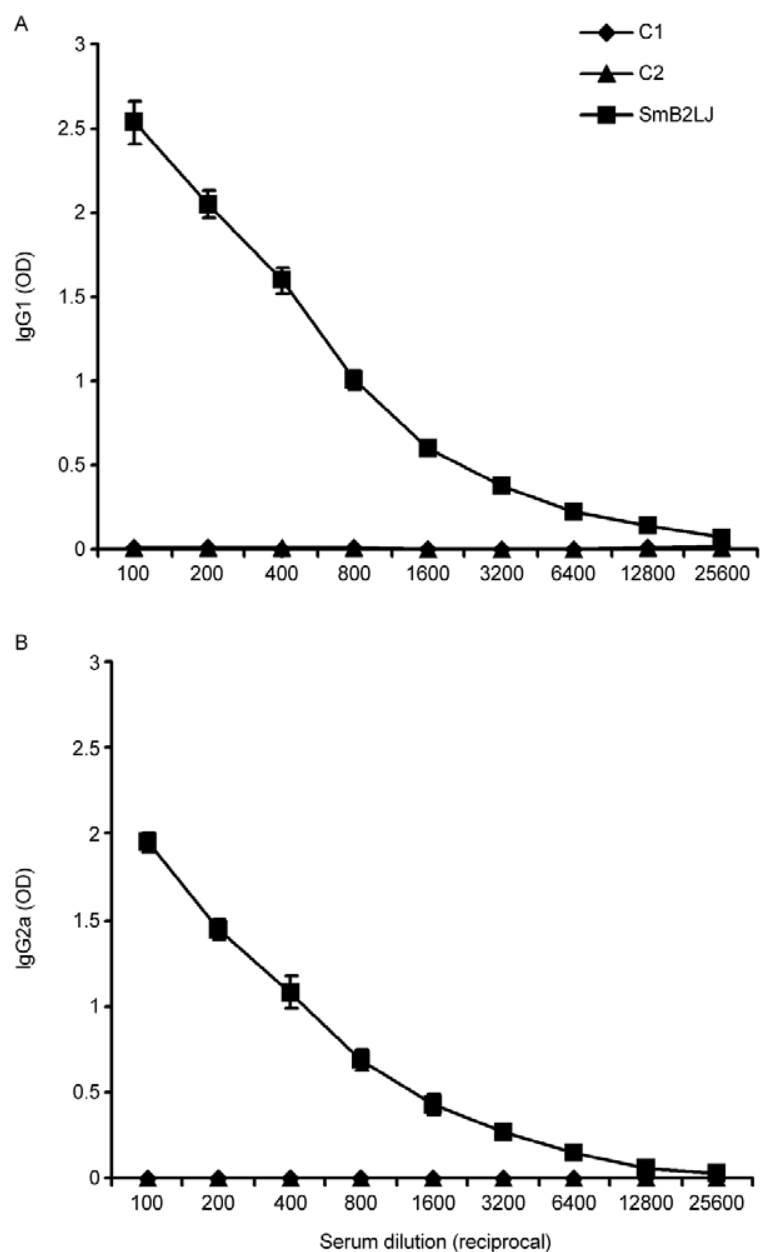

Fig. 1: SmB2LJ stimulatory property. IgG1 (A) and IgG2a (B) subtypes were quantified in serum samples from BALB/c mouse $(n=$ 4) pre-inoculated with SmB2LJ. Pre-immune serum (C1) or serum from $\mathrm{BALB} / \mathrm{c}$ mouse pre-inoculated with Freund incomplete and complete adjuvant $(\mathrm{C} 2)(\mathrm{n}=4)$ was used as control. The serum samples were diluted from 1:100-1:25600 and tested in duplicate. Data are reported as mean \pm standard deviation of optical density (OD). $p$ $<0.05$ for all serum dilutions. 
which were blocked in blocking solution $[0.15 \mathrm{M}$ phosphate buffer solution (PBS), $\mathrm{pH} 7.4,0.3 \%$ Tween-20 and $3 \%$ casein] and further incubated $5 \mathrm{~h}$ at room temperature (RT) with polyclonal mouse anti-SmB2LJ (dil. 1:100) or anti-potato apyrase (dil. 1:1000), and the respective preimmune sera, in the same blocking buffer without Tween20. Assays were developed by chemiluminescence with the specific secondary antibody coupled to horseradish peroxidase and Luminol as substrate using the ECL Western Blotting System (GE Healthcare, Brazil) and exposed to X-ray film following the manufacture's instructions.

Antibody analyses by enzyme-linked immunosorbent assays (ELISA) - An aliquot of potato apyrase or SmB2LJ $(10 \mu \mathrm{g} / \mathrm{mL}$ in $0.1 \mathrm{M} \mathrm{NaHCO}$, pH 9.6) was absorbed overnight onto flat-bottomed microtitre plates (Costar 3590, Corning Inc, Corning, NY, USA). Following incubation in blocking solution (0.15 M PBS, $\mathrm{pH} 7.2,0.3 \%$ Tween20 and $2.5 \%$ casein), the specificity control and/or immune serum samples were diluted (as indicated in Figs $1,2)$ in duplicate in blocking buffer without Tween-20 (Sigma, St. Louis, MO) and incubated for $5 \mathrm{~h}$ at RT. Antibodies bound to the SmB2LJ-plate were detected using peroxidase-conjugated, isotype-specific, anti-mouse total $\mathrm{IgG}$ and o-phenylenediamine dihydrochloride/ $\mathrm{H} 2 \mathrm{O} 2$ (Sigma Chemical Co, USA) as the substrate. The subsequent colour reaction was read at $492 \mathrm{~nm}$ on a microplate reader (Molecular Devices Corp, Menlo Park, CA). The data were analysed using Student's $t$ test and $\mathrm{p}$ values $<$ 0.05 were considered significant.

Polyacrylamide gel electrophoresis and Western blotting of SEA and SWAP - Total proteins $(100 \mu \mathrm{g})$ of SWAP or SEA were dissolved in gel loading buffer and separated by sodium dodecyl sulfate- $10 \%$ polyacrylamide gel electrophoresis using a Mini-Protean III Cell system (Bio-Rad). The gel was electroblotted onto nitro-

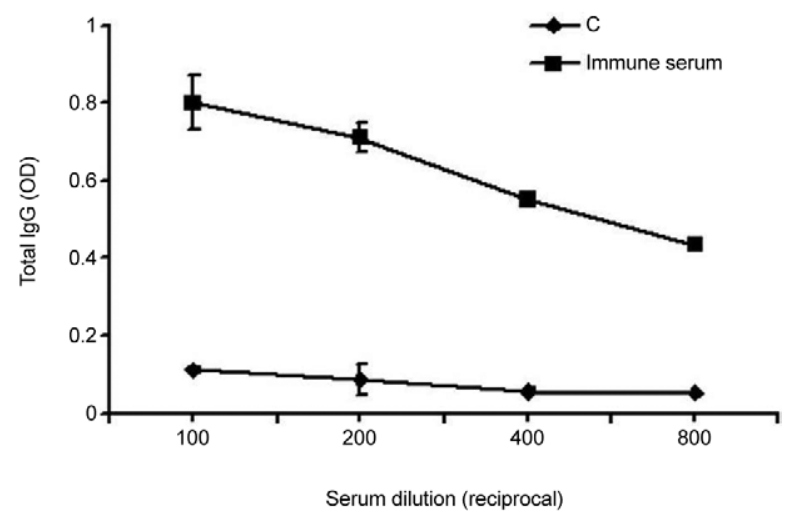

Fig. 2: cross-immunoreactivity between SmB2LJ and mouse polyclonal $\mathrm{IgG}$ anti-potato apyrase. The reactivity of total IgG from BALB/c mice $(n=4)$ pre-inoculated with potato apyrase was tested in enzyme linked immunosorbent assay using SmB2LJ as coating antigen. Pre-immune serum $(C)(n=4)$ obtained before inoculation of potato apyrase was used as control. The serum samples were diluted from 1:100-1:800 and tested in duplicate. Data are reported as mean \pm standard deviation of optical density (OD) $(492 \mathrm{~nm}) . \mathrm{p}<0.001$ for all serum dilutions. cellulose membrane, followed by incubation in blocking buffer (0.15 M PBS, pH 7.4, 0.3\% Tween-20 and 3\% casein) using standard procedures (Faria-Pinto et al. 2004). The membranes were incubated overnight with either pre-immune serum or anti-SmB2LJ immune serum diluted 1:800 in the same blocking buffer without Tween20. As a positive control, the Western blots were also incubated with anti-potato apyrase rabbit polyclonal serum (diluted 1:1000). Assays were developed by chemiluminescence as described above.

Immunohistochemistry - Specimens of mouse liver were removed eight weeks post-infection and frozen in Tissue-Tek OCT Compound by immersion in liquid nitrogen. Cryostat sections ( $10 \mu \mathrm{M}$ thick) were adhered to glass slides previously coated with poly-L-lysine and fixed in acetone for $30 \mathrm{~min}$ at $-20^{\circ} \mathrm{C}$. After drying, the sections were blocked by incubation in PBS containing $2 \%$ skim milk, $2.5 \%$ bovine serum albumin and $8 \%$ fetal calf serum for $45 \mathrm{~min}$ at RT and washed three times in PBS. The sections were then incubated overnight at $4^{\circ} \mathrm{C}$ in PBS containing anti-SmB2LJ diluted 1:400. The slides were washed twice for 15 min each with gentle agitation in PBS and incubated for $60 \mathrm{~min}$ at $37^{\circ} \mathrm{C}$ in PBS containing Alexa Fluor 488 dye conjugated to anti-mouse IgG antibody (Sigma). The slides were washed again as described above before the addition of DABCO. As a control, sections were incubated with secondary antibody alone. To reduce and discriminate the excessive red autofluorescence from the egg-shell, sections were analysed using an inverted confocal laser scanning microscope LSM 510-META Zeiss from the Oswaldo Cruz Institute/Fiocruz, Rio de Janeiro, Brazil.

\section{RESULTS}

Stimulatory property of SmB2LJ and cross-immunoreactivity between this peptide and potato apyrase Polyclonal antiserum against SmB2LJ was obtained from pre-inoculated $\mathrm{BALB} / \mathrm{c}$ mice. These immune sera were initially tested using Dot blots and Fig. 3 shows typical positive results. Dot blots of SmB2LJ were positive for mouse polyclonal IgG anti-SmB2LJ antibodies demonstrating that inoculation of mice with SmB2LJ induced SmB2LJ-specific IgG antibody (Fig. 3C). Levels of IgG subtypes were quantified by ELISA using the diluted serum samples (Fig. 1) (1:100-1:25600). This peptide induced production of elevated levels of the IgG1 and IgG2a subtypes, which were both found to be significantly higher than the controls in all serum dilutions tested $(\mathrm{p}<0.05$ for all IgG subtype vs. control comparisons) (Fig. 1).

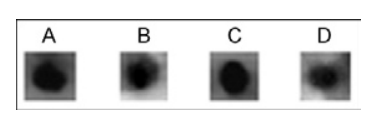

Fig. 3: dot blots of potato apyrase (A, B) $(1 \mu \mathrm{g})$ or SmB2LJ (C, D) $(5 \mu \mathrm{g})$ developed with serum immune from BALB/c mice pre-inoculated with potato apyrase (A, D) (diluted 1:1000) or BALB/c mice preinoculated with SmB2LJ (B, C) (diluted 1:100). The dot blots were incubated for $2 \mathrm{~h}$ at $4^{\circ} \mathrm{C}$ and the signals were revealed by chemiluminescence using peroxidase-conjugated anti-mouse IgG and Luminol as substrate and exposed to X-ray film. 
Dot blots of SmB2LJ were positive for mouse polyclonal IgG anti-potato apyrase (Fig. 3D). The immunological capacity of cross-reactivity between mouse polyclonal IgG anti-potato apyrase and SmB2LJ was quantified using ELISA, employing the peptide as the coating antigen (Fig. 2). Significantly $(\mathrm{p}<0.001)$ higher $\operatorname{IgG}$ antibody reactivity was observed in all serum dilutions (Fig. 2) (dil. 1:100-1:800). In addition, Dot blots of potato apyrase were also positive for mouse polyclonal anti-SmB2LJ antibodies (Fig. 3B), confirming that the epitopes within r175-194 from the S. mansoni SmATPDase 2 are shared with those within r97-116 from the potato apyrase.

Reactivity of mouse polyclonal $\operatorname{Ig} G$ anti-SmB2LJ antibodies against SWAP and SEA - Using Western blot analysis of both SWAP and SEA preparations $(100 \mu \mathrm{g}$ of total protein) (Fig. 4, panel B), mouse polyclonal antiSmB2LJ antibodies recognised bands of approximately 63 and $55 \mathrm{kDa}$, with the lower band possibly representing proteolysis of the $63 \mathrm{kDa}$ band. Rabbit polyclonal anti-potato apyrase antibodies, used as a positive control in this experiment, recognised only the band of approximately $63 \mathrm{kDa}$ in both SEA and SWAP preparations (Fig. 4, panel A). Pre-immune serum diluted 1:800 did not react with SEA or SWAP (data not shown).

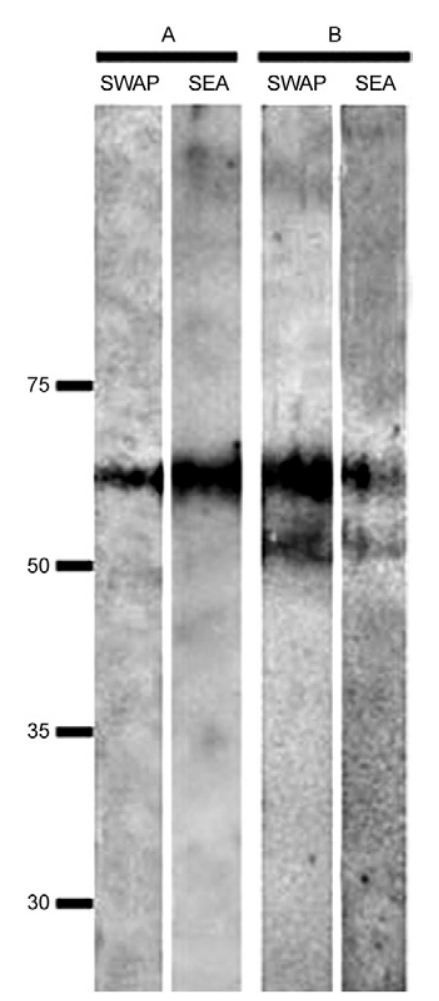

Fig. 4: identification of the ATP diphosphohydrolase soluble isoform in soluble adult worm (SWAP) and egg (SEA) antigens preparations using anti-SmB2LJ antibody. Total proteins $(100 \mu \mathrm{g})$ of SWAP (A, B) or SEA (A, B) were electrophoresed in 10\% sodium dodecyl sulfate$10 \%$ polyacrylamide gel electrophoresis electroblotted onto nitrocellulose membrane and the Western blots were developed with BALB/c mouse polyclonal anti-SmB2LJ (B) (dil. 1:800). Rabbit polyclonal serum against potato apyrase (A) (dil. 1:1000) was used as positive control. The membranes were revealed by chemiluminescence.
Immunolocalisation of the soluble ATP diphosphohydrolase - In order to localise specifically soluble ATP diphosphohydrolase (SmATPDase 2 protein) from the S. mansoni egg, cryostat-labelled sections of infected mouse liver were observed by indirect immunofluorescence using confocal laser scanning microscopy after incubation with anti-SmB2LJ (dil. 1:400) followed by antimouse IgG conjugated to Alexa Fluor 488 dye. As shown in Fig. 5, immunoreactive granular material (green) was visible immediately outside of the egg-shell (B, D, arrows 1 ) and spreading away from the egg-shell, forming deposits in the central periovular area of granulomatous reaction and confirming that the soluble isoform is secreted. This protein was also detected on the external surface of the miracidium (B, D, arrow 2; C, arrow 1) and in von Lichtenberg's envelope, the region between the miracidium and the egg-shell (C, arrows 2). No labelling was observed when samples were incubated with secondary antibody alone (Fig. 5A) and no reactivity was observed in the surrounding granulomatous tissues. Negative reactivity was also observed in hepatic parenchyma, blood vessels and bile ducts (data not shown).
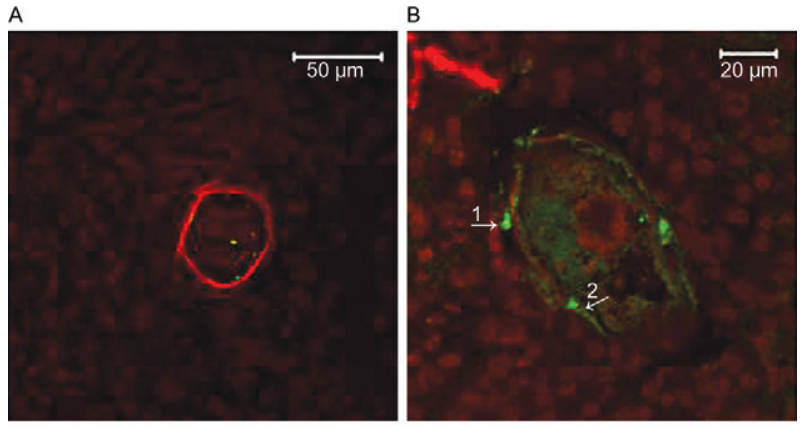

C

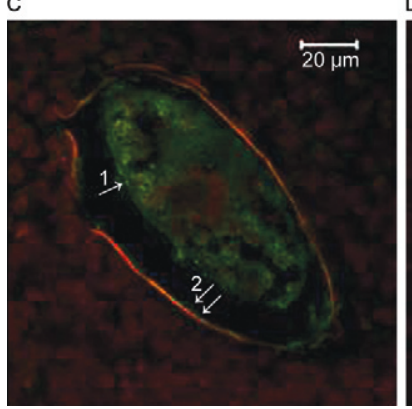

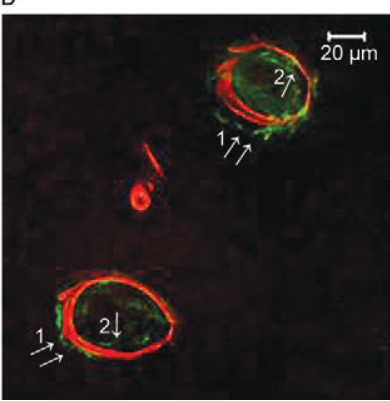

Fig. 5: immunohistochemical localisation of ATP diphosphohydrolase from Schistosoma mansoni egg. Fluorescence confocal microscopy image are shown. BALB/c mouse polyclonal anti-SmB2LJ antibodies (serum diluted 1:400) and secondary antibody coupled to Alexa Fluor 488 were used for fluorescence detection (green) of ATP diphosphohydrolase on cryostat sections $(10 \mu \mathrm{M})$ of infected mouse liver. A: sections were probed with secondary antibody alone; B: general aspect of $S$. mansoni egg showing fluorescence distributed outside from the eggshell (arrow 1) and on the external surface of the miracidium (arrow 2); $\mathrm{C}$ : fluorescence distributed on the external surface of the miracidium (arrow 1) and in von Lichtenberg's envelope located in the region between the miracidium and the inner side of the egg-shell (arrows 2); D: granular material entrapped by the surface microspines located outside the egg-shell and immediately outside and spreading away from the egg-shell (arrows 1) and on the surface of the miracidium (arrows 2). 


\section{DISCUSSION}

In previous work, we characterised an active and soluble ATP diphosphohydrolase isoform of approximately $63 \mathrm{kDa}$ in $S$. mansoni egg, which is antigenic and cross-immunoreactive with potato apyrase (FariaPinto et al. 2004, 2006, 2010a, b). By in silico analysis, a closer structural relationship was described between this vegetable protein and SmATPDase 2, a soluble ATP diphosphohydrolase isoform described in the S. mansoni adult worm. Specific conserved domains were suggested to be potentially involved in the immune response (Faria-Pinto et al. 2008). In an attempt to detect the immune potential of a specific protein domain in studies of schistosomiasis, the synthetic peptide SmB2LJ was obtained. Dot blots of either potato apyrase or SmB2LJ were positive for immune sera against both potato apyrase and SmB2LJ, confirming that the epitopes within r175-194 from the S. mansoni SmATPDase 2 are shared with those within r97-116 from the potato apyrase.

These results also suggest that the conserved domain from the $S$. mansoni SmATPDase 2 is also antigenic and rich in B cell epitopes. SmB2LJ is a peptide of only 20 amino acids belonging to the parasite SmATPDase of 564 amino acids. As demonstrated using Dot blots and ELISA techniques, inoculation of the SmB2LJ peptide in healthy mice has remarkable stimulatory activity, increasing significantly the amount of total $\mathrm{IgG}, \mathrm{IgG} 1$ and IgG2a subtypes, which further support the antigenicity of the domain r175-194 from the soluble $S$. mansoni SmATPDase 2 during schistosomiasis progression. This hypothesis was confirmed by the significant reactivity between SmB2LJ and serum samples from patients with schistosomiasis (unpublished observations).

The SmATPDase 2 protein from the $S$. mansoni adult worm has a predicted molecular weight $63,785 \mathrm{Da}$ and one amino-terminal transmembrane region possibly subject to proteolytic posttranslational processing, resulting in a secreted protein of $55 \mathrm{kDa}$. It was identified by confocal immunofluorescence microscopy in the syncytium and on both apical and basal membranes of the worm tegument (Levano-Garcia et al. 2007). The anti-SmB2LJ antibody recognised in SWAP two bands of approximately $63 \mathrm{kDa}$ and $55 \mathrm{kDa}$, molecular masses similar to those predicted for SmATPDase 2 from the adult worm (Levano-Garcia et al. 2007). Furthermore, the mouse polyclonal anti-SmB2LJ antibodies recognised the same bands in SEA, strongly suggesting the expression of this same isoform in $S$. mansoni eggs.

Definitive proof was obtained from immunolabelled cryostat sections of infected mouse liver by the antiSmB2LJ antibody, which revealed positive reactions on the external surface from the miracidium. The soluble ATP diphosphohydrolase was detected on miracidium at stages 5-7 of embryonic development of the S. mansoni egg, which is when tissue and organ differentiation occurs, and the embryo occupies the internal volume of the egg-shell almost entirely (Jurberg et al. 2009). Intense fluorescence was also detected in the region between the miracidium and the inner side of the egg-shell, located in von Lichtenberg's envelope, which is a region of production of immunogenic components. In addition, fluores- cence was detected in the outer side of the egg-shell and entrapped by the surface microspines, confirming that this protein, like in the adult worm (Levano-Garcia et al. 2007), is also secreted from the S. mansoni eggs. Further immunohistochemical studies using anti-SmB2LJ antibodies should be performed to evaluate the specific role of the soluble ATP diphosphohydrolase in the embryonic development of the $S$. mansoni egg.

A band of $55 \mathrm{kDa}$, possibly resultant of an in vivo proteolysis and that was in lower amounts than that of $63 \mathrm{kDain}$ these antigenic preparations, was also recognised by the immune serum anti-SmB2LJ, but not by immune serum against potato apyrase. In previous work, we showed that rabbit polyclonal anti-potato apyrase antibodies did not recognise mammalian NTPDases (FariaPinto et al. 2006) and, in this study, similar results were observed. No reactivity was observed in the surrounding granulomatous tissues, which are rich in inflammatory cells such as macrophages, eosinophils, neutrophils, lymphocytes, mast cells and fibroblastic-like cells (Lenzi et al. 1998). In addition, the domain from the either mouse NTPDase 5 or NTPDase 6 , two intracellular members of the ATP diphosphohydrolase family (Robson et al. 2006), has lower identity and similarity with its $S$. mansoni SmATPDase 2 counterpart. Although we cannot disregard the possibility of cross-immunoreactivity between anti-SmB2LJ and mammalian NTPDases 5 and 6 that are possibly not accessible under our experimental conditions, our results suggest that autoantibodies against mammalian NTPDases are not induced during SmB2LJ experimental immunisation. All together, these data show specificity, sensitivity and affinity of the mouse polyclonal anti-SmB2LJ antibody for the epitopes within r175-194 from the S. mansoni SmATPDase 2 and reinforce the importance of our immunological results.

Our results suggested epitopes within this peptide are capable of inducing a Th1- or Th2-type immune response. IgG2a, a Th1 cytokine-derived isotype, has been described as being protective against schistosomula and adult worms, possibly through antibody-dependent cell cytotoxic mechanisms, whereas IgG1, a Th2 cytokinederived isotype, has been associated with the immunomodulation of the granulomatous inflammation in schistosomiasis (Mountford et al. 1994, Coelho et al. 1996, James et al. 1998, Zouain et al. 2000, Carvalho-Queiroz et al. 2004, Kusel et al. 2007, Oliveira et al. 2008). The epitopes within soluble ATP diphosphohydrolase from the $S$. mansoni egg described here, as well as within SmATPDase 2 from the cercariae, schistosomula and adult worm (Levano-Garcia et al. 2007), could be related to the success of the parasitism through disease immunomodulation during the course of the parasitic infection. Different levels of $\operatorname{IgG}$ isotypes against potato apyrase have been demonstrated before and after chemotherapy in experimental schistosomiasis and patients (Faria-Pinto et al. 2010a, b). Identifying epitopes within an antigen is important for the possibility of constructing vaccines with relevant peptides able to induce protective responses, as well as immunotherapy formulations with epitope modulators of the inflammatory response (Oliveira et al. 2008, Cardoso et al. 2010). Therefore, the peptide Sm- 
B2LJ could be useful as a compound to improve diagnostic method, immunotherapy or vaccine formulations, and experiments testing these hypotheses are currently being carried out in our laboratory.

\section{ACKNOWLEDGEMENTS}

To PDTIS/Fiocruz, for use of its facilities.

\section{REFERENCES}

Cardoso LS, Oliveira SC, Góes AM, Oliveira RR, Pacífico LG, Marinho FV, Fonseca CT, Cardoso FC, Carvalho EM, Araujo MI 2010. Schistosoma mansoni antigens modulate the allergic response in a murine model of ovalbumin-induced airway inflammation. Clin Exp Immunol 160: 266-274.

Carvalho-Queiroz C, Cook R, Wang CC, Correa-Oliveira R, Bailey NA, Egilmez NK, Mathiowitz E, LoVerde PT 2004. Cross-reactivity of Schistosoma mansoni cytosolic superoxide dismutase, a protective vaccine candidate, with host superoxide dismutase and identification of parasite-specific B epitopes. Infect Immun 72: 2635-2647.

Coelho PM, Toppa NH, Feldmann JS, Gonçalves R, Mello RT 1996. Schistosoma mansoni: permanence of modulation of the granulomatous inflammatory response in mice cured in the chronic phase. Int J Parasitol 26: 1393-1395.

Colley DG, Cook JA, Freeman GL Jr, Bartholomew RK, Jordan P 1977. Immune responses during human schistosomiasis mansoni. I. In vitro lymphocyte blastogenic responses to heterogeneous antigenic preparations from schistosome eggs, worms and cercariae. Int Arch Allergy Appl Immunol 53: 420-433.

DeMarco R, Kowaltowski AT, Mortara RA, Verjovski-Almeida S 2003. Molecular characterization and immunolocalization of Schistosoma mansoni ATP-diphosphohydrolase. Biochem Biophys Res Commun 307: 831-838.

Faria-Pinto P, Meirelles MN, Lenzi HL, Mota EM, Penido MLO, Coelho PMZ, Vasconcelos EG 2004. ATP diphosphohydrolase from Schistosoma mansoni egg: characterization of a new antigen. Parasitology 129: 51-57.

Faria-Pinto P, Meirelles MNL, Lenzi HL, Mota EM, Penido MLO, Coelho PMZ, Vasconcelos EG 2006. Cross-immunoreactivity between anti-potato apyrase antibodies and mammalian ATP diphosphohydrolases: potential use of the vegetal protein in experimental schistosomiasis. Mem Inst Oswaldo Cruz 101 (Suppl. I): 359-363.

Faria-Pinto P, Mendes RG, Carvalho-Campos C, Maia AC, Oliveira AA, Coelho PM, Vasconcelos EG 2010a. Detection of IgG1 and IgG4 subtypes reactive against potato apyrase in schistosomiasis patients. Mem Inst Oswaldo Cruz 105: 370-373.

Faria-Pinto P, Montesano MA, Jacinto AA, Santos RS, Bordin FHS, Ferreira AP, Penido MLO, Coelho PMZ, Vasconcelos EG 2010b. Antibody reactivity against potato apyrase, a protein that shares epitopes with Schistosoma mansoni ATP diphosphohydrolase isoforms, in acute and chronically infected mice after chemotherapy and reinfection. Mem Inst Oswaldo Cruz 105: 374-379.

Faria-Pinto P, Rezende-Soares FA, Molica AM, Montesano MA, Marques MJ, Rocha MO, Gomes JA, Enk MJ, Correa-Oliveira R, Coelho PM, Neto SM, Franco OL, Vasconcelos EG 2008. Mapping of the conserved antigenic domains shared between potato apyrase and parasite ATP diphosphohydrolases: potential application in human parasitic diseases. Parasitology 135: 943-953.

James SL, Cheever AW, Caspar P, Wynn TA 1998. Inducible nitric oxide synthase-deficient mice develop enhanced type 1 cytokineassociated cellular and humoral immune responses after vaccination with attenuated Schistosoma mansoni cercariae but display partially reduced resistance. Infect Immun 66: 3510-3518.

Jurberg AD, Gonçalves T, Costa TA, de Mattos AC, Pascarelli BM, de Manso PP, Ribeiro-Alves M, Pelajo-Machado M, Peralta JM,
Coelho PM, Lenzi HL 2009. The embryonic development of Schistosoma mansoni eggs: proposal for a new staging system. Dev Genes Evol 219: 219-234.

Kettlun AM, Espinosa V, García L, Valenzuela MA 2005. Potato tuber isoapyrases: substrate specificity, affinity labelling and proteolytic susceptibility. Phytochemistry 66: 975-982.

Korkmaz B, Attucci S, Juliano MA, Kalupov T, Jourdan ML, Juliano L, Gauthier F 2008. Measuring elastase, proteinase 3 and cathepsin $\mathrm{G}$ activities at the surface of human neutrophils with fluorescence resonance energy transfer substrates. Nat Protoc 3: 991-1000.

Kusel JR, Al-Adham BH, Doenhoff MJ 2007. The schistosome in the mammalian host: understanding the mechanisms of adaptation. Parasitology 134: 1477-1526.

Lenzi HL, Kimmel E, Schechtman H, Pelajo-Machado M, Romanha WS, Pacheco RG, Mariano M, Lenzi JA 1998. Histoarchitecture of schistosomal granuloma development and involution: morphogenetic and biomechanical approaches. Mem Inst Oswaldo Cruz 93 (Suppl. I): 141-151.

Levano-Garcia J, Mortara RA, Verjovski-Almeida S, DeMarco R 2007. Characterization of Schistosoma mansoni ATPDase2 gene, a novel apyrase family member. Biochem Biophys Res Commun 352: 384-389.

Mountford AP, Fisher A, Wilson RA 1994. The profile of IgG1 and IgG2a antibody responses in mice exposed to Schistosoma mansoni. Parasite Immunol 16: 521-527.

Oliveira SC, Fonseca CT, Cardoso FC, Farias LP, Leite LC 2008. Recent advances in vaccine research against schistosomiasis in Brazil. Acta Trop 108: 256-262.

Penido ML, Resende DM, Vianello MA, Bordin FHS, Jacinto AA, Dias WD, Montesano MA, Nelson DL, Coelho PMZ, Vasconcelos EG 2007. A new series of schistosomicide drugs, the alkylaminoalkanethiosulfuric acids, partially inhibit the activity of Schistosoma mansoni ATP diphosphohydrolase. Eur J Pharmacol 570: 10-17.

Robson SC, Sévigny J, Zimmermann H 2006. The E-NTPDase family of ectonucleotidases: structure function relationships and pathophysiological significance. Purinergic Signal 2: 409-430.

Sansom FM, Robson SC, Hartland EL 2008. Possible effects of microbial ecto-nucleoside triphosphate diphosphohydrolase on hostpathogen interactions. Microbiol Mol Biol Rev 72: 765-781.

Smithers SR, Terry RJ 1965. The infection of laboratory hosts with cercariae of Schistosoma mansoni and the recovery of adult worms. Parasitology 55: 695-700.

Vasconcelos EG, Faria-Pinto P, Rezende-Soares FA, Penido ML, Gonçalves-da-Costa SC, Coelho PMZ 2009. Potato apyrase: a new tool for parasitic disease research. In P Tennant, N Benkeblia (eds.), Potato II. Fruit, vegetable and cereal science and biotechnology 3, (special issue 1), Global Science Books, Ikenobe, p. 80-88.

Vasconcelos EG, Ferreira ST, Carvalho TM, Souza W, Kettlun AM, Mancilla M, Valenzuela MA, Verjovski-Almeida S 1996. Partial purification and immunohistochemical localization of ATP diphosphohydrolase from Schistosoma mansoni. Immunological cross-reactivities with potato apyrase and Toxoplasma gondii nucleoside triphosphate hydrolase. J Biol Chem 271: 22139-22145.

Vasconcelos EG, Nascimento PS, Meirelles MN, Verjovski-Almeida S, Ferreira ST 1993. Characterization and localization of an ATPdiphosphohydrolase on the external surface of the tegument of Schistosoma mansoni. Mol Biochem Parasitol 58: 205-214.

Zouain CS, Gustavson S, Oliveira SC, Azevedo V, Alves JB, Goes AM 2000. The role of IL-10 and IgG1 in the protection and granulomatous response in Schistosoma mansoni P24-immunized mice. Vaccine 19: 1218-1224. 